\title{
Idiopathic Hypertrophic Cranial Pachymeningitis Associated With Total Occlusion of the Dural Sinuses
}

-Case Report-

\author{
Yoshitsugu OIWA, Genhachi HYOTANI*, Ichiro KAMEI*, and Toru ITAKURA \\ Department of Neurological Surgery, Wakayama Medical University, Wakayama; \\ ${ }^{*}$ Department of Neurosurgery, Japanese Red Cross Society Wakayama Medical Center, Wakayama
}

\begin{abstract}
A 44-year-old man presented with a rare case of idiopathic hypertrophic cranial pachymeningitis manifesting as generalized seizure. Neuroimaging and pathological examinations showed the typical features of hypertrophic cranial pachymeningitis. Tuberculosis was a possible cause based on the positive purified protein-derived skin test, but the origin of the disease was not confirmed by further examinations. Cerebral angiography showed total occlusion of the dural sinuses with development of the emissary veins. Histological examination of the dura showed thickening of the fibrous tissue with rare inflammatory cells, suggestive of the extremely long duration of the disease. The diagnosis was idiopathic hypertrophic cranial pachymeningitis, but was treated only with anticonvulsants. The disease did not progress during follow up of 3 years. Idiopathic hypertrophic cranial pachymeningitis may have various causes related to unusual forms of infectious or autoimmune disorders.
\end{abstract}

Key words: dura mater, inflammation, seizure, venous infarction, thrombosis

\section{Introduction}

Hypertrophic cranial pachymeningitis (HCP) is a rare inflammatory disease, but the frequency of detection has increased since the development of magnetic resonance (MR) imaging. The disease is infrequently associated with infectious, neoplastic, or autoimmune inflammatory diseases such as tuberculosis, syphilis, sarcoidosis, Wegener's

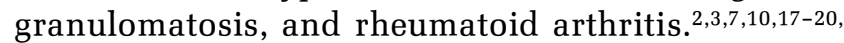
25,26,32) However, the etiology of HCP is quite often not identified, resulting in a diagnosis of idiopathic HCP. The symptoms of HCP are thought to result most commonly from inflammation or compression of the cranial nerves by the affected dura. Moreover, occlusion of the intracranial vessels, the internal carotid arteries, ${ }^{6,29,31)}$ or the dural sinuses, ${ }^{1,4,5,9,11}$, $14-16,30)$ is also known. Some cases may be related to Tolosa-Hunt syndrome, orbital pseudotumor, or multifocal fibrosclerosis. ${ }^{22,29)}$ The disease progresses gradually in most cases, but the outcome is variable.

We treated a patient with idiopathic HCP associated with total occlusion of the dural sinuses with the development of collateral venous circulation,

Received January 9, 2004; Accepted July 5, 2004 suggesting an extremely long clinical course.

\section{Case Report}

A 44-year-old Japanese man suffered generalized seizure originating from his right hand, and felt numbness of the right extremities after the seizure ceased. He had a history of generalized seizure since the age of 24 years. On admission, neurological examination showed no abnormal findings. Hematological examinations revealed temporary elevation of white blood cell count and C-reactive protein level. However, all immunological tests showed negative findings, including antinuclear antibody titers, rheumatoid factor titers, and the Treponema pallidum hemaglutinine test. Fluorescent treponemal antibody for absorbed serum tests were also negative for the blood and the cerebrospinal fluid (CSF). Angiotensin-converting enzyme level in the serum was within the normal limits. The purified protein-derived (PPD) skin test was positive, but tuberculosis genomic deoxyribonucleic acid (DNA) was not detected by polymerase chain reaction (PCR) in either the sputum or CSF. The cell counts and adenosine deaminase level were normal, but the protein level was slightly elevated to $63 \mathrm{mg} / \mathrm{dl}$ 

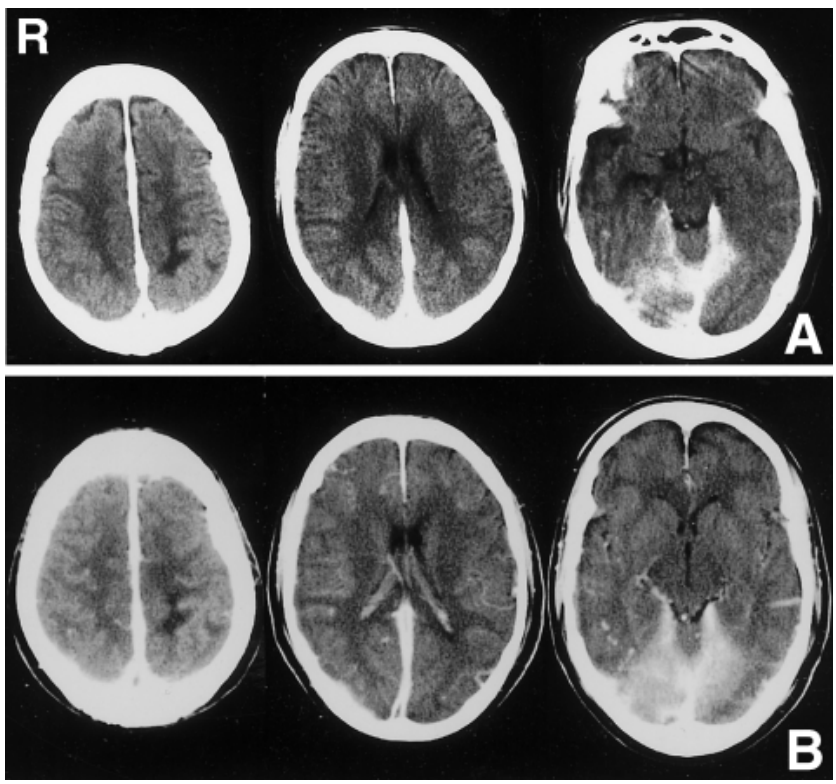

Fig. 1 A: Head computed tomography (CT) scans showing the falx and the tentorium as marked high density. B: CT scans with contrast medium showing additional enhancement of the meninges. Note absence of enhancement of the superior sagittal sinus.

in the CSF

Chest radiography showed no abnormalities. Electroencephalography showed sporadic $\delta$-waves over the left frontoparietal regions. Head computed tomography (CT) demonstrated the dura mater including the falx and the tentorium as high density, accompanied by absence of enhancement of the superior sagittal sinus (Fig. 1). $\mathrm{T}_{2}$-weighted $\mathrm{MR}$ imaging showed the thickened dura as hypointense. $\mathrm{T}_{1}$-weighted $\mathrm{MR}$ imaging with gadoliniumdiethylenetriaminepenta-acetic acid showed the dura with intense enhancement (Fig. 2). Moreover, $\mathrm{T}_{2}$-weighted $\mathrm{MR}$ imaging suggested dilated pial veins over the cerebral cortex and an ischemic lesion in the white matter of the left parietal lobe. Internal carotid angiography demonstrated total occlusion of all dural sinuses, and venous flows draining through the dilated cortical veins to the emissary veins (Fig. 3). The internal jugular veins were not opacified. Bilateral internal and external carotid angiography showed no abnormality of the arterial vessels.

Trephination at the right parietal area was performed for biopsy of the meninges. Histological examination showed thickening of the dura with fibrous proliferation, which was sparsely associated with cell infiltration (Fig. 4). The arachnoid
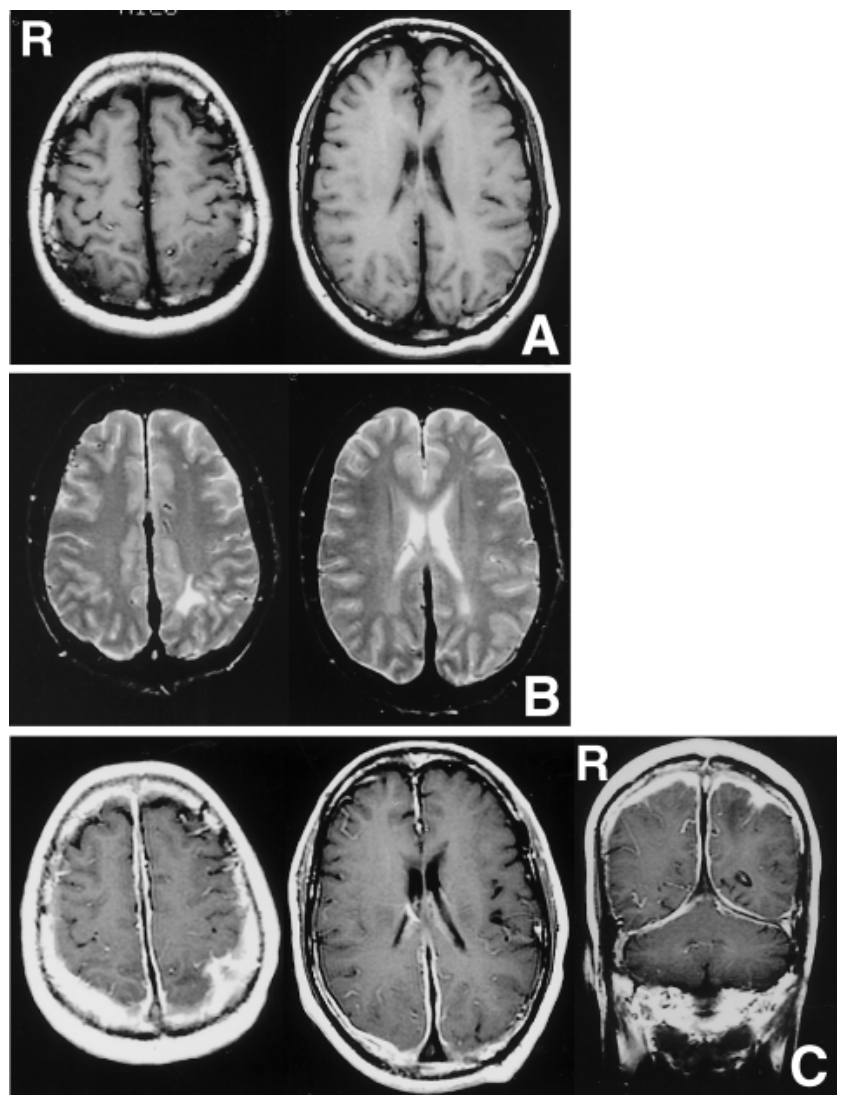

Fig. 2 A: Axial $\mathrm{T}_{1}$-weighted magnetic resonance (MR) images showing the thickened falx and the dura as hypointense, with signal voids of the dilated cerebral veins over the cerebral cortex. B: Axial $\mathrm{T}_{2}$-weighted MR images showing the falx and the dura as markedly hypointense, with a hyperintense area in the parietal white matter on the left. $C$ : Axial and coronal $T_{1}$-weighted $M R$ images with gadolinium showing meningeal enhancement over the cerebral cortex.

membrane was also thickened with proliferation of arachnoid cells and perivascular infiltration of lymphocytes. There was no formation of granulomas, and Ziehl-Neelsen staining for acid-fast bacilli was negative. The diagnosis was idiopathic HCP with venous infarction. Anticonvulsants, phenytoin (300 mg/day) and phenobarbital (90 mg/day), were administered to treat the focal seizure, but neither corticosteroids nor antituberculous drugs were used because of the absence of active inflammatory changes. The patient has not experienced seizures during a 3-year follow-up period, and subsequent MR imaging showed no change. 

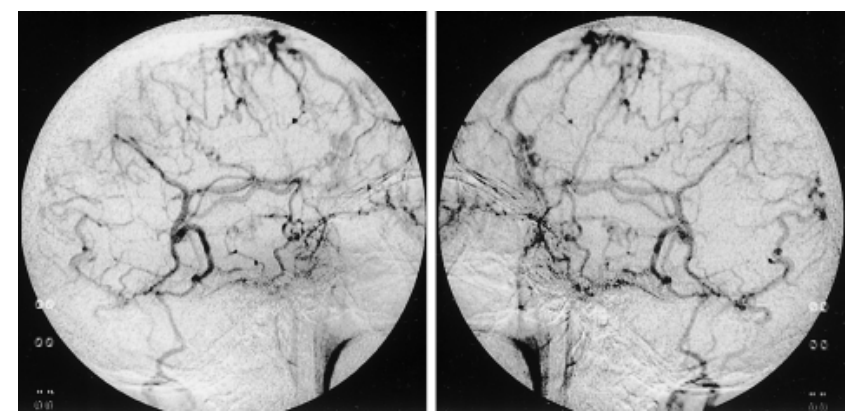

Fig. 3 Right (left) and left (right) internal carotid angiograms showing total occlusion of the dural sinuses associated with bilateral development of the cortical veins. The venous circulation was drained from the cranium through the emissary veins.
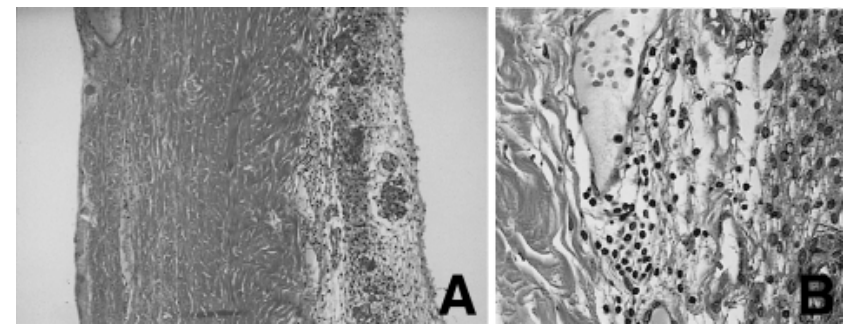

Fig. 4 Photomicrographs of the biopsy specimen of the meninges showing mild thickening of the dura with fibrous proliferation, and thickened arachnoid attached to the dura (A: hematoxylin-eosin stain, $\times 50$ ), and proliferation of the arachnoid cells in the perivascular areas (B: hematoxylin-eosin stain, $\times 200$ ).

\section{Discussion}

Forty-five cases of idiopathic HCP detected since the introduction of MR imaging are shown in Table 1.1,4-6,8,9,11,13-16,20,21,23,24,28-31) There was no sex or age association among the patients. The diagnosis of idiopathic HCP was established after the exclusion of obvious causes in all cases. Histological examination of the dura showed nonspecific inflammatory changes associated with lymphocytic infiltration and granuloma formation, whereas the brain parenchyma or skull bone was rarely involved. ${ }^{11,16,20)} \mathrm{CT}$ and MR imaging showed characteristic findings for the meningeal lesions. $\mathrm{T}_{2^{-}}$ weighted MR imaging showed the thickened dura as hypointense, probably resulting from the proliferation of collagenous tissue. ${ }^{14)} \mathrm{CT}$ showed the lesion as high density. Blood vessels were frequently surrounded by inflammatory lesions, such as the inter-
Table 1 Summary of 45 reported cases of idiopathic hypertrophic cranial pachymeningitis*

\begin{tabular}{|c|c|}
\hline Male/Female & $23 / 22$ \\
\hline Mean age (range) & $50.9 \pm 16.4(19-78)$ years \\
\hline Duration of disease & 1 week-10 years \\
\hline \multicolumn{2}{|l|}{ Symptoms } \\
\hline headache or orbital pain & 33 \\
\hline cranial nerve disturbance & 32 \\
\hline ataxia & 5 \\
\hline seizures & 3 \\
\hline hypopituitarism & 3 \\
\hline cortical signs & 2 \\
\hline \multicolumn{2}{|l|}{ Associated lesions } \\
\hline sinus occlusion & 13 \\
\hline ICA stenosis or occlusion & 5 \\
\hline sinusitis & 6 \\
\hline otitis media & 3 \\
\hline \multicolumn{2}{|l|}{ Treatments } \\
\hline corticosteroids & 37 (21 dependent) \\
\hline immunosuppressants & 12 \\
\hline antituberculous drugs & 3 \\
\hline anticonvulsants & 2 \\
\hline surgical decompression & 6 \\
\hline Duration of follow up & 1 month-14 years \\
\hline \multicolumn{2}{|l|}{ Outcome } \\
\hline improved or stable & 31 \\
\hline fluctuating or progressive & 9 \\
\hline dead & 5 \\
\hline
\end{tabular}

nal carotid arteries (5 cases) or dural sinuses (13 cases). Inflammatory changes of the paranasal sinuses or middle ear cavities were found in 11 of the 45 patients. Chronic infections in these areas may be related to HCP, but the pathogenic mechanism is unknown. The neuroradiological features in our patient showed the typical findings of HCP but suggested an extremely long course of the disease as suggested by the development of venous drainage through the emissary veins.

The most common symptoms were headache (33 of 45 cases) and cranial nerve pareses ( 32 of 45 ), but the length of the clinical course was not uniform. The follow-up periods also varied. Most patients initially responded to drug therapy, but remained dependent on corticosteroids. Nine of the 45 patients showed fluctuations of symptoms, and surgical resection of granulomas was occasionally required to reduce compression on the neuronal tissues. ${ }^{5,9,13,16,20,29)}$ Five of the 45 patients died. Three patients had epileptic seizures, but two had stable clinical courses as they did not receive corticosteroids. ${ }^{15,16,30)}$ The variety of clinical features 
implies the involvement of various causes in idiopathic HCP.

One patient with HCP died of head trauma during a seizure. ${ }^{10)}$ The dural sinuses appeared to be totally occluded with fibrous thickening and thrombosis, which were identical to the findings of syphilitic HCP. ${ }^{7)}$ However, Treponema pallidum was difficult to detect in their specimen, although the patients were positive for hematological tests.

Tuberculosis is another common cause of HCP and occasionally shows similar MR imaging findings as in our case. ${ }^{2)}$ Although tuberculous disease was possibly present in our patient because of the positive PPD test, further examinations were negative. Tuberculous HCP usually appears as a severe illness of the central nervous system, but diagnosis may be difficult during the inactive phase of inflammation. Only $20 \%$ of patients with tuberculous meningitis can be diagnosed by PCR for tuberculous DNA. ${ }^{27)}$ In addition, the adenosine deaminase level of the CSF is high in the early stage of inflammation associated with the activities of T-lymphocytes, but decreases when the T-cells are inactivated. ${ }^{12)}$ Three patients responded to antituberculous drugs, suggesting that the standard tests are not sensitive enough to detect inactive tuberculous HCP. ${ }^{8,15,23)}$

Hematological examinations and biopsy confirmed the absence of evidence of meningeal sarcoidosis in our patient. Neurosarcoidosis rarely presents as fibrous thickening of the meninges appearing as hypointense on $\mathrm{T}_{2}$-weighted $\mathrm{MR}$ imaging. ${ }^{25,26)} \mathrm{CSF}$ examination may support the diagnosis if pleocytosis is detected, even biopsy specimens are frequently negative, depending upon the stage of the disease.

The present case of idiopathic HCP had an extremely long course of the disease. The cause of HCP could not be confirmed because of the absence of active inflammation in the biopsy specimen. Previous cases and our present case suggest that idiopathic HCP had various causes related to unusual forms of infectious or autoimmune disorders.

\section{References}

1) Bang OY, Kim DI, Yoon SR, Choi IS: Idiopathic hypertrophic pachymeningeal lesions: correlation between clinical patterns and neuroimaging characteristics. Eur Neurol 39: 49-56, 1998

2) Callebaut J, Dormont D, Chiras B, Bories J: Contrastenhanced MR imaging of tuberculous pachymeningitis cranialis hypertrophica: case report. AJNR Am J Neuroradiol 11: 821-822, 1990

3) Deprez M, Born J, Hauwaert C, Otto B, Reznik M: Idiopathic hypertrophic cranial pachymeningitis mimicking multiple meningiomas: case report and review of the literature. Acta Neuropathol (Berl) 94: 385-389, 1997

4) Goyal M, Malik A, Mishra NK, Galikwad SB: Idiopathic hypertrophic pachymeningitis: spectrum of the disease. Neuroradiology 39: 619-623, 1997

5) Hamada J, Yoshinaga Y, Korogi Y, Ushio Y: Idiopathic hypertrophic cranial pachymeningitis associated with a dural arteriovenous fistula involving the straight sinus: case report. Neurosurgery 47 : 1230-1233, 2000

6) Hamilton SR, Smith $\mathrm{CH}$, Lessell S: Idiopathic hypertrophic cranial pachymeningitis. J Clin Neuroophthalmol 13: 127-134, 1993

7) Hassin GB, Zeitlin H: Syphilitic cerebral hypertrophic pachymeningitis: clinicopathological studies in a case. Arch Neurol Psychiatry 43: 362-371, 1940

8) Hatano N, Behari S, Nagatani T, Kimura M, Ooka K, Saito K, Yoshida J: Idiopathic hypertrophic cranial pachymeningitis: Clinicoradiological spectrum and therapeutic options. Neurosurgery 45: 1336-1344, 1999

9) Kadoya C, Soejima T, Yamada H, Yokota A: Pachymeningoencephalitis: case report. Neurosurgery 33: 131-135, 1993

10) Kuramochi S, Hosoda $Y$, Matsuyama H, Shinohara Y: Thromboendophlebitis obliterans of the dural sinuses associated with hypertrophic pachymeningitis. Vasc Surg 13: 104-110, 1979

11) Lee YC, Chueng YC, Hsu SW, Lui CC: Idiopathic hypertrophic cranial pachymeningitis: case report with 7 years of imaging follow-up. AJNR Am J Neuroradiol 24: 119-123, 2003

12) Malan C, Donald PR, Golden M, Taljaard JJ: Adenosine deaminase levels in cerebrospinal fluid in the diagnosis of tuberculous meningitis. J Trop Med Hyg 87: 33-40, 1984

13) Mamelak AN, Kelly WM, Davis RL, Rosenblum ML: Idiopathic hypertrophic cranial pachymeningitis. Report of three cases. J Neurosurg 79: 270-276, 1993

14) Martin N, Masson C, Henin D, Mompoint D, Marsault C, Nahum H: Hypertrophic cranial pachymeningitis: assessment with $\mathrm{CT}$ and $\mathrm{MR}$ imaging. AJNR Am J Neuroradiol 10: 477-484, 1989

15) Masson C, Henin D, Hauw JJ, Rey A, Raverdy P, Masson M: Cranial pachymeningitis of unknown origin: a study of seven cases. Neurology 43: 1329-1334, 1993

16) Mizumatsu S, Michiue $H$, Suga $M$, Sunami $N$, Yamamoto Y: [A case of hypertrophic cranial pachymeningitis developed skull lesion]. No To Shinkei 52: 1103-1108, 2000 (Jpn, with Eng abstract)

17) Moore AP, Rolfe EB, Jones EL: Pachymeningitis cranialis hypertrophica. J Neurol Neurosurg Psychiatry 48: 942-944, 1985

18) Murai H, Kira J, Kobayashi T, Goto I, Inoue H, Hasuo K: Hypertrophic cranial pachymeningitis due to Aspergillus flavus. Clin Neurol Neurosurg 94: 247-250, 1992

19) Nagashima $T$, Maguchi $S$, Terayama $Y$, Horimoto $M$, Nemoto M, Nunomura M, Mori M, Seki T, 
Matsukawa S, Itoh T, Nagashima K: P-ANCApositive Wegener's granulomatosis presenting with hypertrophic pachymeningitis and multiple cranial neuropathies: case report and review of literature. Neuropathology 20: 23-30, 2000

20) Nakazaki H, Tanaka T, Isoshima A, Hida T, Nakajima M, Abe T: Idiopathic hypertrophic cranial pachymeningitis with perifocal brain edema - case report. Neurol Med Chir (Tokyo) 40: 239-243, 2000

21) Nishioka $H$, Ito $H$, Haraoka J, Takahashi $M$, Shinmura F: Idiopathic hypertrophic cranial pachymeningitis of the cavernous sinus mimicking lymphocytic hypophysitis - case report. Neurol Med Chir (Tokyo) 38: 377-382, 1998

22) Olmos PR, Falko JM, Rea GL, Boesel CP, Chakeres DW, McGhee DB: Fibrosing pseudotumor of the sella and parasellar area producing hypopituitarism and multiple cranial nerve palsies. Neurosurgery 32: 1015-1021, 1993

23) Parney IF, Johnson ES, Allen PBR: "Idiopathic" cranial hypertrophic pachymeningitis responsive to antituberculous therapy: case report. Neurosurgery 41: 965-971, 1997

24) Phanthumchinda K, Sinsawaiwong S, Hemachudha T, Yodnophaklao P: Idiopathic hypertrophic cranial pachymeningitis: an unusual cause of subacute and chronic headache. Headache 37: 249-252, 1997

25) Ranoux D, Devaux B, Lamy C, Mear JY, Roux FX, Mas JL: Meningeal sarcoidosis, pseudo-meningioma, and pachymeningitis of the convexity. J Neurol Neurosurg Psychiatry 55: 300-303, 1992

26) Seltzer S, Mark AS, Atlas SW: CNS sarcoidosis: evaluation with contrast-enhanced MR imaging. AJNR Am J Neuroradiol 12: 1227-1233, 1991
27) Shankar P, Manjunath N, Lakshmi R, Aditi B, Seth P, Shriniwas: Identification of Mycobacterium tuberculosis by polymerase chain reaction. Lancet 335(8686): 423, 1990

28) Shintani S, Shiigai T, Tsuruoka S: Hypertrophic cranial pachymeningitis causing progressive unilateral blindness: MR findings. Clin Neurol Neurosurg 95: 65-70, 1993

29) Sumida M, Taguchi H, Eguchi K, Kuroki K: [A case of idiopathic cranial hypertrophic pachymeningitis presenting Tolosa-Hunt syndrome]. No To Shinkei 52: 523-527, 2000 (Jpn, with Eng abstract)

30) Takahashi M, Sasajima T, Mineura K, Itoh $Y$, Kowada M, Iwaya K, Hatazawa J, Ogawa T, Okudera T, Murakami M, Uemura K: [Positron emission tomographic evaluation for frontal hypertrophic cranial pachymeningitis using 11C-methyl-L-methionine]. No Shinkei Geka 24: 287-293, 1996 (Jpn, with Eng abstract)

31) Willing SJ, Broghamer W: Internal carotid artery occlusion due to idiopathic cranial pachymeningitis. AJNR Am J Neuroradiol 13: 1594-1596, 1992

32) Yuh WTC, Drew JM, Rizzo M, Ryals T, Sato Y, Bell WE: Evaluation of pachymeningitis by contrastenhanced imaging in a patient with rheumatoid disease. AJNR Am J Neuroradiol 11: 1247-1248, 1990

Address reprint requests to: Y. Oiwa, M.D., Department of Neurological Surgery, Wakayama Medical University, 811-1 Kimiidera, Wakayama 641-0012, Japan. e-mail: oiwa@wakayama-med.ac.jp 